\title{
Effects of caloric restriction on oxidative stress parameters
}

\author{
Marija Stankovic ${ }^{1}$, Dusan Mladenovic ${ }^{1}$, Milica Ninkovic ${ }^{2}$, Danijela Vucevic ${ }^{1}$, Tina Tomasevic ${ }^{1}$ \\ and Tatjana Radosavljevic ${ }^{1}$ \\ ${ }^{1}$ Institute of Pathophysiology, Faculty of Medicine, University of Belgrade, Dr Subotica 9, Belgrade, Serbia \\ ${ }^{2}$ Military Medical Academy, Crnotravska 17, Belgrade, Serbia
}

\begin{abstract}
Moderate caloric restriction prolongs lifespan. Changes in oxidative stress and hormesis may be involved in this process. The aim of this study is to examine the effects of different levels of chronic caloric restriction (CR) and acute fasting on stress response and oxidative stress parameters in rat liver and plasma. Forty-two rats were divided into groups: control group, calorie-restricted groups with intake of $80-90 \%, 60-70 \%, 40-50 \%, 20-30 \%$ of daily caloric needs and acute fasting group. To determine alanine aminotransferase (ALT), aspartate aminotransferase (AST) and superoxide dismutase (SOD) activity, concentration of corticosterone, nitrites and nitrates $\left(\mathrm{NO}_{\mathrm{x}}\right)$, malondialdehyde (MDA) and glutathione (GSH), liver samples and blood were collected. Increase in plasma corticosterone concentration and AST and ALT activity was found in severe CR. Ingestion $40-50 \%$ daily caloric needs or less increased liver $\mathrm{MDA}$ and $\mathrm{NO}_{\mathrm{x}}$ concentration and decreased SOD activity. Ingestion 60-70\% daily caloric needs increased $\mathrm{Mn}-\mathrm{SOD}$ activity, GSH and $\mathrm{NO}_{\mathrm{x}}$. In acute fasting group and group taking 20-30\% daily caloric needs, GSH was significantly lower than in control group. Severe CR and acute fasting increase oxidative damage and decrease antioxidative capacity of hepatocytes. Moderate CR increases antioxidative capacity of hepatocytes due to increase in Mn-SOD activity and GSH concentration, which might have a role in anti-aging and hormetic mechanism of CR.
\end{abstract}

Key words: Caloric restriction - Oxidative stress - Hormesis - Acute fasting

\begin{abstract}
Abbreviations: ALT, alanine aminotransferase; AST, aspartate aminotransferase; $\mathrm{CR}$, caloric restriction; DTNB, 5,5'-dithiobis-(2-nitrobenzoic acid); eNOS, endothelial nitric oxide synthase; GSH, glutathione; IGF-1, insulin-like growth factor 1; Keap 1, Kelchlike ECH-associated protein 1; MDA, malondialdehyde; mTOR, mammalian target of rapamycin; Nrf2, NF-E2-related factor 2; ROS, reactive oxygen species; SIRT1, Sirtuin 1; SOD, superoxide dismutase.
\end{abstract}

\section{Introduction}

Moderate caloric restriction has been shown to decrease incidence of age-related diseases, including cardiovascular diseases, diabetes mellitus type 2 and cancer, and to increase lifespan (Weindruch and Sohal 1997; Masoro 2005; Mesquita et al. 2010; Ristow and Schmeisser 2011). The precise mechanism of anti-aging effect of caloric restriction

Correspondence to: Marija Stankovic, University of Belgrade, Faculty of Medicine, Institute of pathophysiology, Dr Subotica 9, 11000 Belgrade, Serbia

E-mail: marija.stankovic.med@gmail.com
(CR) is still unknown. Possible explanations are alteration of the insulin-like growth factor 1 (IGF-1) signaling (Bluher et al. 2003; Ristow and Schmeisser 2011), sirtuin 1 (SIRT1) and mammalian target of rapamycin (mTOR) (Colman et al. 2009), activation of the NF-E2-related factor 2/Kelchlike ECH-associated protein 1 (Nrf2/Keap1) (Birringer 2011), or inhibition of stress-induced apoptotic cell death (Cohen et al. 2004). The effect of CR on oxidative stress (OS) parameters in organism and hormesis might have a role in anti-aging mechanism of CR (Hunt et al. 2011).

One of theories of aging is the free radical theory. The concept of this theory is that if metabolic rate is increased, more reactive oxygen species (ROS) will be produced and 
hence it will cause cumulative cellular oxidative damage (Ristow and Zarse 2010). However, there is also the opinion that moderate CR actually acts like a low-level stress that induces ROS defense mechanism and increases stress resistance (Ristow and Zarse 2010).

Phenomenon that low dose of stressor has beneficial effects on cell, leads to increased stress resistance and promotes longevity is hormesis (Masoro 1998a,b; Radak et al. 2008; Le Bourg 2009; Marques et al. 2009). So far, it has been shown that applying low doses of stressor that has toxic effect at high doses induce adaptive response in different organisms, such as prokaryotes, yeasts, plants, intervertebrates and mammals. These effects were observed in humans as well (Calabrese et al. 2007; Gems and Partridge 2008; Colman et al. 2009; Marques et al. 2009). CR, irradiation, cold, heat, hyperbaric oxygen and chemicals such as paraquat or juglone have been proved as hormetic stressors (Marques et al. 2009; Hunt et al. 2011).

A lot of researches about hormesis were done, but the precise mechanism of hormesis is still unknown (Marques et al. 2009). Considering CR as a hormetic stressor, it is supposed that CR increases mitochondrial activity and ROS formation, and subsequent induction of ROS defense mechanisms (Birringer 2011; Ristow and Schmeisser 2011).

Although some experiments about aging and hormesis were carried out on rodents, most of them were done on invertebrate species such as Drosophila melanogaster or the nematode Caenorhabditis elegans (Le Bourg 2009). Therefore we have performed experiment on rats and examined the effects of different levels of chronic CR and acute fasting on OS parameters in rat liver and plasma, in order to better understand mechanism of hormetic effect of CR. Additionally, plasma corticosterone concentration was measured as an indicator of stress and activities of aspartate aminotransferase (AST) and alanine aminotransferase (ALT) in plasma were measured as indicators of hepatocytes damage (Waite et al. 2002).

Also, to our knowledge, the effects of all different levels of CR which we had examined in this experiment, on oxidative stress parameters have not been analyzed in one study yet.

\section{Materials and Methods}

Ten weeks old male Wistar rats (200-220 g) used in this study were bred at Military Medical Academy in Belgrade. The rats were maintained under standard conditions, temperature 22 $\pm 2^{\circ} \mathrm{C}$, relative humidity $50 \%$, in $12 \mathrm{~h}$ light/dark cycle with free access to tap water. This study was performed respecting The European Council Directive (86/609/EC) and was approved by The Ethic Committee of Faculty of Medicine, University of Belgrade.
Forty-two animals were divided into following groups: control group $(n=7)$, four calorie-restricted groups receiving 80-90\% (CR80-90, $n=7$ ), 60-70\% (CR60-70, $n=7$ ), $40-50 \%(\mathrm{CR} 40-50, n=7)$ and $20-30 \%$ (CR20-30, $n=7)$, of daily caloric needs during 5 weeks and acute fasting group $((n=7)$, one week without food intake).

Food restriction was calculated according to recommended food intake for ten weeks old rats which is $17 \mathrm{~g}$ of pelleted food. The diet consisted of maximum of $7 \%$ cellulose and minimum of $19 \%$ of proteins. Control group had recommended food intake.

After finishing the treatment, mild ether anesthesia was used and animals were sacrificed by decapitation. Liver samples and blood from the right side of the heart were collected for analyzing OS parameters, plasma corticosterone concentration, plasma AST and ALT activity.

Liver samples for biochemical analysis were homogenized on ice, in cold buffered 0.25 M sucrose medium (Serva Feinbiochemica, Heidelberg, NY, USA) with $10 \mathrm{mM}$ phosphate buffer (pH 7.0) and 1 mM EDTA (Sigma-Aldrich Chemical Co., St. Louis, USA). The homogenates were centrifuged at $2000 \times g$ for $15 \mathrm{~min}$ at $4^{\circ} \mathrm{C}$. After centrifugation, sediments were dissolved in the sucrose medium and re-centrifuged as previously indicated. The supernatant was transferred into the tubes and centrifuged at $3200 \times g$ for $30 \mathrm{~min}$ at $4^{\circ} \mathrm{C}$. Obtained sediments were dissolved in deionized water. After 1 hour of incubation at $4^{\circ} \mathrm{C}$, the samples were centrifuged again at 3000 $\times g$ for $15 \mathrm{~min}$ at $4^{\circ} \mathrm{C}$, and supernatants were stored at $-70^{\circ} \mathrm{C}$. To determine proteins, the Lowry method with bovine serum albumin as the standard was used (Lowry et al. 1951).

Blood samples were collected from the right side of the heart into heparinized test tubes.

Activities of AST and ALT in plasma, as indicators of hepatocytes damage (Waite et al. 2002), were measured by spectrophotometer (Biosystems, BTS-330) and commercial kits (Sigma Chem. Co. St. Louis, USA). Plasma corticosterone concentration, as an indicator of stress (Waite et al. 2002), was measured by radioimmunoassay using tubes labeled with rabbit anti-corticosterone-antibodies.

Concentration of nitrites and nitrates $\left(\mathrm{NO}_{\mathrm{x}}\right)$ in liver, indicators of NO oxide production (Cuzzocrea et al. 2003) was measured with Griess reagent. Reacting with $\mathrm{NO}_{\mathrm{X}}$, Griess reagent forms a purple colored compound and color intensity was measured spectrophotometrically (Biosystems, BTS-330) at $492 \mathrm{~nm}$ (Hibbs et al. 1989).

Total superoxide dismutase (SOD) activity in liver was measured spectrophotometrically (Biosystems, BTS-330) at $480 \mathrm{~nm}$, as the percentage of inhibition of adrenaline autooxidation. After adding $10 \mathrm{mM}$ of adrenaline (Sigma, St. Luis, USA), analysis was performed in the sodium carbonate buffer (50 mM, pH 10.2; Serva, Feinbiochemica, Heidelberg, New York) containing $0.1 \mathrm{mM}$ ethylenediaminetetraacetic acid (Sigma, St. Luis, USA) (Sun and Zigman 1978). To 
determine manganese superoxide dismutase (Mn-SOD) activity, samples were first treated with $8 \mathrm{mM}$ potassium cyanide (Sigma, St. Luis, USA) and then analyzed as Sun and Zigman had described (Sun and Zigman 1978).

Lipid peroxidation was determined by measuring concentration of malondialdehyde (MDA), as Girroti and co-workers had described. Thiobarbituric acid reacting with MDA formed yellow colored compound and its absorbance was measured spectrophotometrically (Biosystems, BTS-330) at $533 \mathrm{~nm}$ (Girroti et al. 1991).

Glutathione (GSH) concentration was determined by using Ellman's reagent (5,5'-dithiobis-(2-nitrobenzoic acid) or DTNB) in Tris-HCl buffer. DTNB in Tris- $\mathrm{HCl}$ buffer reacted with thiols groups in GSH, formed yellow colored nitro-thio-benzoate ion and color intensity was measured by spectrophotometer (Biosystems, BTS-330) at $412 \mathrm{~nm}$ (Anderson, 1986).

\section{Statistical analysis}

Data were presented as mean \pm standard deviation. Differences between groups were tested by the one-way analysis of variance followed by the Fisher's post hoc test. $p<0.05$ was considered statistically significant. SPSS 15.0 program was used for the statistical analysis.

\section{Results}

There was no significant difference in AST and ALT activity in plasma between control group, CR60-70 group and CR80-90 group $(p>0.05)$. On the other hand, AST and ALT activity in plasma was significantly higher in CR40-50, CR20-30 and acute fasting group in comparison to control group (Table 1).

Table 1. Effects of different levels of caloric restriction and fasting on ALT and AST activity in rat plasma

\begin{tabular}{lll}
\hline Group & ALT (U/l) & AST (U/l) \\
\hline Control & $36.4 \pm 3.3$ & $50.6 \pm 4.1$ \\
CR80-90 & $34.7 \pm 3.2$ & $47.2 \pm 3.9$ \\
CR60-70 & $38.1 \pm 2.9$ & $48.8 \pm 2.9$ \\
CR40-50 & $62.7 \pm 4.8^{*}$ & $62.8 \pm 5^{\dagger}$ \\
CR20-30 & $67.9 \pm 5.4^{*}$ & $68.3 \pm 4.8^{*}$ \\
Acute fasting & $66.4 \pm 5.7^{*}$ & $69.5 \pm 4.3^{*}$ \\
\hline
\end{tabular}

Value is mean \pm standard deviation. AST, aspartate aminotransferase; ALT, alanine aminotransferase; CR20-30, calorie-restricted group receiving $20-30 \%$ of daily caloric needs; CR40-50, calorie-restricted group receiving $40-50 \%$ of daily caloric needs; CR60-70, calorie-restricted group receiving $60-70 \%$ of daily caloric needs; CR80-90, calorie-restricted group receiving $80-90 \%$ of daily caloric needs. ${ }^{*} p<0.01$ compared to control group; $\uparrow p<0.05$ compared to control group.
Corticosterone concentration in plasma was significantly higher in CR60-70, CR40-50, CR20-30 and acute fasting group than in control group $(391.21 \pm 16.77 \mathrm{ng} / \mathrm{ml}, 519.00$ $\pm 11.83 \mathrm{ng} / \mathrm{ml} ; 527.01 \pm 26.69 \mathrm{ng} / \mathrm{ml} ; 603.13 \pm 17.09 \mathrm{ng} / \mathrm{ml}$; respectively) $(p \leq 0.01)$, while there was no significant difference between control group and CR80-90 group (282.07 \pm $13.48 \mathrm{ng} / \mathrm{ml} ; 289.02 \pm 12.96 \mathrm{ng} / \mathrm{ml}$; respectively). Corticosterone concentration was higher in CR40-50 and CR20-30 in comparison to CR60-70 ( $p \leq 0.01)$. Additionally, the highest level of plasma corticosterone was detected in acute fasting group (Figure 1).

There was no significant difference in MDA concentration between control group $(2.86 \pm 0.80 \mu \mathrm{mol} / \mathrm{mg}$ prot. $)$, CR60-70 group ( $4.17 \pm 0.69 \mu \mathrm{mol} / \mathrm{mg}$ prot.) and CR80-90 group (3.39 $\pm 0.86 \mu \mathrm{mol} / \mathrm{mg}$ prot.) $(p>0.05)$. In CR40-50, CR20-30 and acute fasting groups significantly higher MDA concentrations in liver $(16.15 \pm 0.93 \mu \mathrm{mol} / \mathrm{mg}$ prot.; 30.08 $\pm 4.76 \mu \mathrm{mol} \mathrm{mg}$ prot. and $27.00 \pm 7.38 \mu \mathrm{mol} / \mathrm{mg}$ prot., respectively) were detected in comparison to MDA concentration in control group $(p \leq 0.01)$. On the other hand, there is no significant difference in MDA liver concentration between CR20-30 group and acute fasting group ( $p>$ 0.05) (Figure 2).

In our study, $\mathrm{NO}_{\mathrm{x}}$ concentration in liver was significantly higher in groups CR60-70 (7.45 $\pm 1.99 \mu \mathrm{mol} / \mathrm{mg}$ prot.; $p<0.05)$, CR40-50 (33.65 $\pm 11.05 \mu \mathrm{mol} / \mathrm{mg}$ prot.; $p<0.01)$, CR20-30 (35.79 $\pm 6.25 \mu \mathrm{mol} / \mathrm{mg}$ prot.; $p<0.01)$ and acute fasting group $(35.05 \pm 6.76 \mu \mathrm{mol} / \mathrm{mg}$ prot.; $p<$ $0.01)$ than in control group (5.00 $\pm 1.79 \mu \mathrm{mol} / \mathrm{mg}$ prot.). In comparison to CR60-70 group, NOx concentration in liver in CR40-50, CR20-30 and acute fasting group was

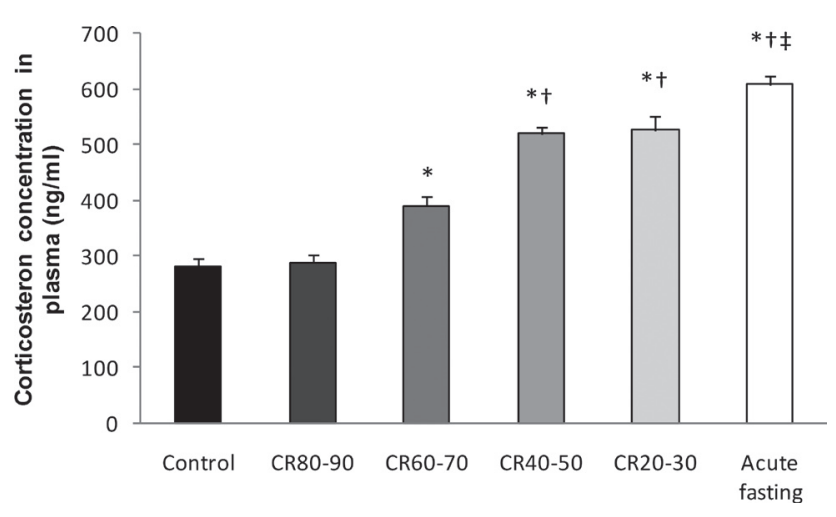

Figure 1. Effects of different levels of caloric restriction and acute fasting on corticosterone concentration in rat plasma. ${ }^{*} p<0.01$ compared to control group; $\dagger p<0.01$ compared to CR60-70; $\ddagger p<0.01$ compared to CR20-30. CR20-30, calorie-restricted group receiving $20-30 \%$ of daily caloric needs; CR40-50, calorie-restricted group receiving $40-50 \%$ of daily caloric needs; CR60-70, calorierestricted group receiving 60-70\% of daily caloric needs; CR80-90, calorie-restricted group receiving $80-90 \%$ of daily caloric needs. 


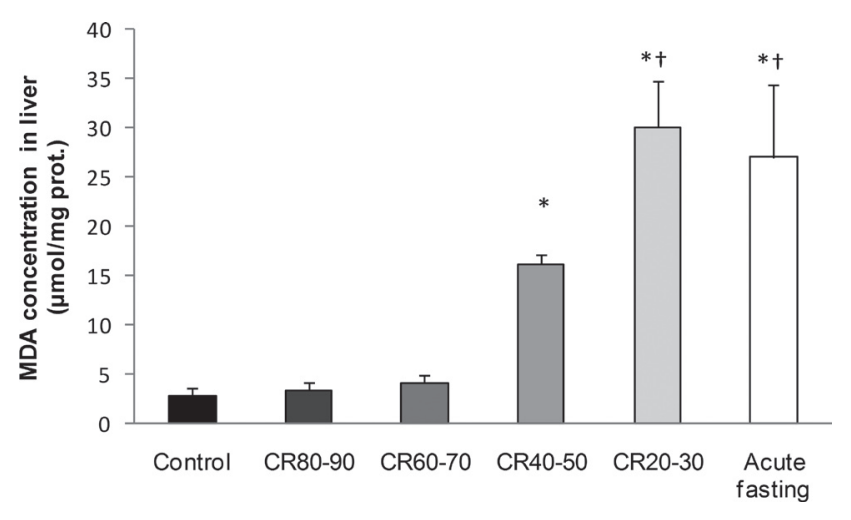

Figure 2. Effects of different levels of caloric restriction and acute fasting on malondialdehyde (MDA) concentration in rat liver. ${ }^{*} p<0.01$ compared to control group; $\dagger p<0.01$ compared to CR40-50. (For abbreviations see Fig. 1).

significantly higher $(p<0.01)$. There was no significant difference, considering NOx level in liver, between CR8090 group $(5.19 \pm 1.56 \mu \mathrm{mol} / \mathrm{mg}$ prot.) and control group $(p>0.05)$ (Figure 3$)$.

SOD activity in liver was significantly lower in acute fasting group (1643.08 $\pm 80.69 \mathrm{U} / \mathrm{mg}$ prot.), CR20-30 (1487.98 $\pm 75.12 \mathrm{U} / \mathrm{mg}$ prot.) and CR40-50 group (1614.01 \pm 99.46 $\mathrm{U} / \mathrm{mg}$ prot.), comparing to control group (1892.34 \pm 96.34 $\mathrm{U} / \mathrm{mg}$ prot.; $p<0.01$ ). Moreover, activity of the examined enzyme was the lowest in CR20-30 group. In contrast, when CR80-90 (1863.74 $\pm 82.08 \mathrm{U} / \mathrm{mg}$ prot.) and CR60-70 (1924.87 $\pm 91.32 \mathrm{U} / \mathrm{mg}$ prot.) groups were compared to control group no significant difference in SOD activity in liver was detected $(p>0.05)$ (Figure 4).

Activity of SOD isoform, $\mathrm{Cu} / \mathrm{Zn}$-SOD was changing in the same manner as total SOD activity (Figure 4).

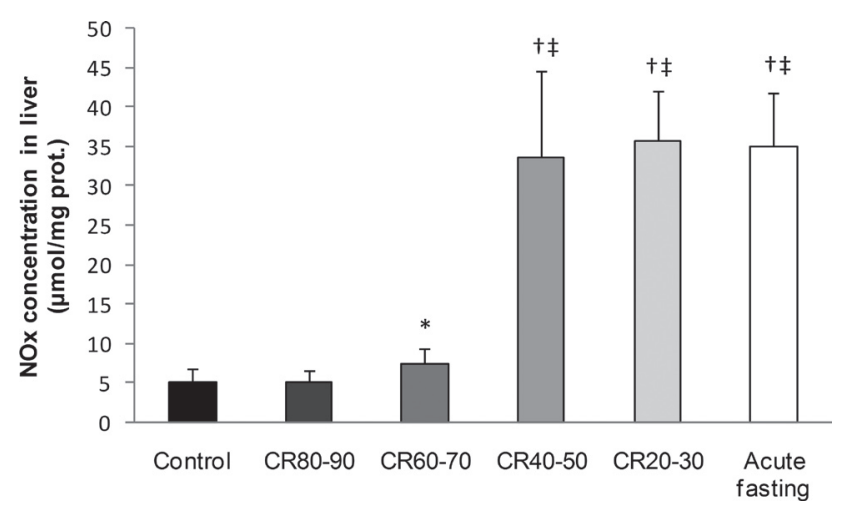

Figure 3. Effects of different levels of caloric restriction and acute fasting on concentration of nitrites and nitrates $\left(\mathrm{NO}_{\mathrm{x}}\right)$ concentration in rat liver. ${ }^{\star} p<0.05$ compared to control group; $\dagger p<0.01$ compared to control group; $\ddagger p<0.01$ compared to CR60-70. For abbreviations see Fig. 1).
Activity of mitochondrial SOD isoform, Mn-SOD in liver was significantly higher in CR60-70 group (193.45 \pm 11.13 $\mathrm{U} / \mathrm{mg}$ prot.) than in control group $(124.08 \pm 8.65 \mathrm{U} / \mathrm{mg}$ prot.; $p<0.01)$. Mn-SOD activity in liver was significantly lower in groups CR40-50 (98.02 $\pm 7.12 \mathrm{U} / \mathrm{mg}$ prot.), CR2030 group $(80.63 \pm 8.05 \mathrm{U} / \mathrm{mg}$ prot.) and acute fasting group (92.74 $\pm 6.51 \mathrm{U} / \mathrm{mg}$ prot.), comparing to control group, but also comparing to CR60-70 group. There was no significant difference in Mn-SOD activity in liver between CR40-50 and acute fasting group $(p>0.05)$, as well as between CR40-50 and CR20-30 ( $p>0.05)$ (Figure 5).

GSH concentration in liver was significantly higher in CR60-70 group (1.73 $\pm 0.10 \mathrm{nmol} / \mathrm{mg}$ prot.) than in control group $(1.16 \pm 0.09 \mathrm{nmol} / \mathrm{mg}$ prot.; $p<0.01)$. On the other hand, it was detected significant decrease in GSH concentration in CR20-30 group ( $0.54 \pm 0.03 \mathrm{nmol} / \mathrm{mg}$ prot.) and acute fasting group $(0.57 \pm 0.04 \mathrm{nmol} / \mathrm{mg}$ prot. $)$, in comparison to control group $(p<0.01)$. Comparing control group to CR80-90 group $(1.08 \pm 0.11 \mathrm{nmol} / \mathrm{mg}$ prot.) and to CR40-50 group (1.07 $\pm 0.09 \mathrm{nmol} / \mathrm{mg}$ prot.), no significant differences in GSH concentration in liver were found $(p>$ 0.05) (Figure 6).

\section{Discussion}

In our study, ALT and AST activity in plasma (indicators of hepatocyte damage) was not increased in CR60-70 and CR80-90, which might indicate that moderete and mild caloric restriction had not caused hepatocytes damage. In contrast to, ALT and AST activity in plasma was increased in acute fasting group, CR20-30 and CR40-50 groups, which led us to conclusion that intensive CR and acute fasting had caused hepatic damage.

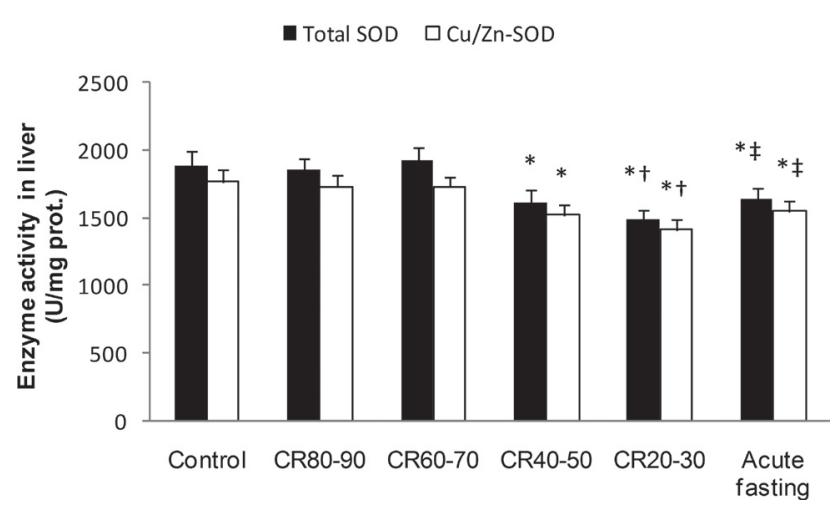

Figure 4. Effects of different levels of caloric restriction and acute fasting on total superoxide dismutase (SOD) and $\mathrm{Cu} / \mathrm{Zn}$-SOD activity in rat liver. ${ }^{\star} p<0.01$ compared to control group; $\dagger p<0.01$ compared to CR40-50; $\neq p<0.01$ compared to CR20-30. (For abbreviations see Fig. 1). 
In present experiment, plasma corticosterone concentration increased when the calorie intake was restricted for $30 \%$ and more of recommended calorie intake, indicating that moderate and intensive chronic CR were stressful for organism. On the other hand, the highest concentration of corticosterone was in acute fasting group, meaning that acute fasting is a stronger stressor than chronic caloric restriction. Similar to our results, Chacón and co-workers reported increased plasma corticosterone level in rats after 4 weeks receiving $66 \%$ of recommended caloric needs (Chacón et al. 2005). Increased plasma corticosterone level was also reported in rats whose food intake during 14 days was reduced for $25 \%$ and $50 \%$, comparing to control group (Ling and Bistrian 2009).

When animals in our study were fed with $50 \%$ and less of recommended daily caloric intake, MDA concentration in liver, as one of the measures of lipid peroxidation in liver, was progressively increasing. After one week of fasting, MDA liver level increased, while Abdelmegeed et al. reported that shorter period of fasting was not long enough to cause increase in lipid peroxidation, actually 36 -h fasting did not significantly changed MDA concentration in mouse liver, comparing to control group (Abdelmegeed et al. 2009). After 12 months receiving $60 \%$ of the energy intake in control group, lipid peroxidation in rat muscle mitochondria even decreased for $46 \%$ in comparison to control group, suggesting protective role of this level of caloric restriction (Bevilacqua et al. 2005). On the other hand, after 18 months taking $40 \%$ less food than control group, lipid peroxidation was not changed in rat liver (Abdelmegeed et al. 2009). Similar to this result, in our study rats who were fed with $80-90 \%$ and $60-70 \%$ of daily recommended food intake did not have a significant changes in MDA liver concentration, comparing to control group.

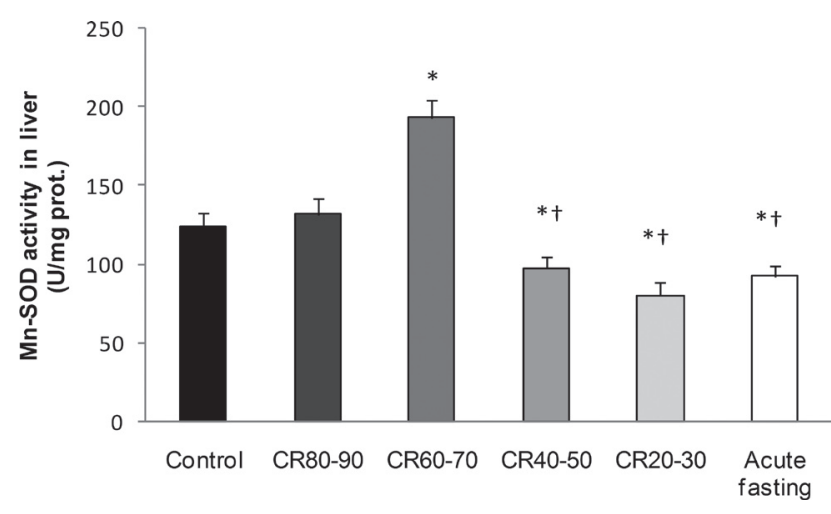

Figure 5. Effects of different levels of caloric restriction and acute fasting on manganese superoxide dismutase (Mn-SOD) activity in rat liver. ${ }^{\star} p<0.01$ compared to control group; $\dagger p<0.01$ compared to CR60-70. (For abbreviations see Fig. 1).

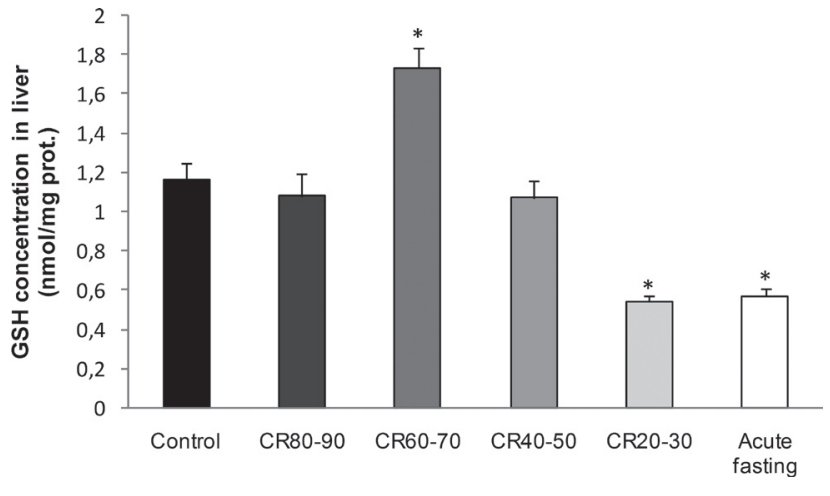

Figure 6. Effects of different levels of caloric restriction and acute fasting on glutathione (GSH) concentration in rat liver. ${ }^{\star} p<0.01$ compared to control group. (For abbreviations see Fig. 1).

$\mathrm{NO}_{\mathrm{x}}$ concentration in liver significantly increased in CR60-70 group, when compared to control group. Since ALT and AST activity, as indicators of hepatocyte damage were not increased, explanation for $\mathrm{NO}_{\mathrm{x}}$ increase may be that moderate $\mathrm{CR}$ induces endothelial nitric oxide synthase (eNOS) and consequently that low increase in NO level may have protective effect and may prevent age-related changes in blood vessels (Nisoli et al. 2005). Our results have shown that $\mathrm{NO}_{\mathrm{x}}$ concentration in liver is significantly increased in rats with chronic CR for $50 \%$ and more, as well as in acute fasting group. These results may support suggestion that $\mathrm{NO}_{\mathrm{X}}$ have important role in hepatocyte damage in intensive calorie restriction (Clemens 1999) since we have shown that AST and ALT activity are increased in groups CR40-50, CR20-30 and acute fasting group.

In our experiment taking $50 \%$ of recommended daily calorie intake or less significantly decreased SOD activity in liver. The explanation for this result might be that in contrast to mild and moderate chronic CR, intensive chronic CR as well as acute fasting, cause decrease in antioxidative liver capacity. SOD activity was lower in CR20-30 than in acute fasting group which means that chronic, intensive CR decreased antioxidative liver protection even more than acute fasting. Similar, SOD activity in liver was also decreased in mice, after 36-h fasting (Abdelmegeed et al. 2009). Although we did not reported any significant differences comparing SOD activity in group CR60-70 to SOD activity in control group, 18-month-old rats received $60 \%$ of the food given to control group had significantly increased hepatic SOD activity comparing to control group (Hamden et al. 2009). It was also reported that liver tissue of the rats fed with $60 \%$ of the diet of the rats fed ad libitum, at 21 and 28 months of age had significantly higher SOD activity (24\% and $38 \%$, respectively) comparing to rats fed ad libitum (Rao et al. 1990) which may also be explanation for protective effect of moderate CR. 
In our study, the activity of SOD isoform, citosol enzyme $\mathrm{Cu} / \mathrm{Zn}$-SOD was changing in the same manner as activity of total SOD. On the other hand, the same changes were not reported considering activity of another SOD isoform, mitochondrial Mn-SOD. Our results showed that moderate CR (CR60-70) leads to increased Mn-SOD activity in liver. Since the most of ROS are produced in mitochondria, increased Mn-SOD activity may be one of hormetic mechanisms of moderate CR. On the other hand, intensive CR led to decreased Mn-SOD activity, which supports idea of $\mathrm{CR}$ as a hormetic factor. One of the explanations for this result might be that the enzyme was used for neutralizing ROS formed due to intensive CR. Another possible explanation for decreased Mn-SOD activity is nitrosilation of this enzyme and its inactivation by $\mathrm{NO}_{\mathrm{x}}$ formed in intensive CR.

In our study, hepatic GSH concentration in CR60-70 was significantly higher than in control group. Similar to this result, Laganiere and Yu reported increase in hepatic GSH concentration in rats fed with $60 \%$ of the mean caloric intake of ad libitum fed group for 24 months (Laganiere and $\mathrm{Yu}$ 1989). Since GSH is antioxidant and important for neutralizing ROS (Pompella et al. 2003), increased GSH concentration may be also one of hormetic mechanisms of moderate CR. On the other hand, in CR20-30 and fasting group was detected significantly lower GSH concentration in comparison to control group. Abdelmegeed et al. (2009) also reported significant decrease in liver GSH level in mouse after 36-hour-fasting. These findings indicate that those levels of CR cause decrease in anti-oxidative liver capacity.

In conclusion, moderate $\mathrm{CR}$ triggers stress response, since it caused increase in plasma corticosterone concentration. This level of CR did not increase AST and ALT activities and MDA concentration in liver, which means that moderate CR does not cause hepatocyte damage and does not increase lipid peroxidation in liver. On the other hand, moderate CR increases hepatic antioxidant capacity, $\mathrm{Mn}-\mathrm{SOD}$ activity and GSH concentration in liver, which, in our opinion, might have the role in anti-aging and hormetic effect of CR

Acknowledgements: This research was supported by Ministry of Education and Science, Serbia; Grant \#175015.

\section{References}

Abdelmegeed M., Moon K. H., Hardwick J., Gonzalez F., Song B. J. (2009): Role of peroxisome proliferator/activated receptor$\alpha$ in fasting/mediated oxidative stress. Free Radic. Biol. Med. 46, 767-778 http://dx.doi.org/10.1016/j.freeradbiomed.2009.06.017

Anderson M. E. (1986): Tissue glutathione: The DTNB-GSSG reductase recycling assay for total glutathione $(\mathrm{GSH}+$
1/2GSSG). In: Handbook of Methods for Oxygen Radical Research (Eds. R. A. Greenwald), pp. 317-323, CRC Press, Boca Raton, FL

Bevilacqua L., Ramsey J. J., Hagopian K., Weindruch R., Harper M. E. (2005): Long-term caloric restriction increases UCP3 content but decreases proton leak and reactive oxygen species production in rat skeletal muscle mitochondria. Am. J. Physiol. Endocrinol. Metab. 289, E429-438 http://dx.doi.org/10.1152/ajpendo.00435.2004

Birringer M. (2011): Hormetics: dietary triggers of an adaptive stress response. Pharm. Res. 28, 2680-2694 http://dx.doi.org/10.1007/s11095-011-0551-1

Bluher M., Kahn B. B., Kahn R. C. (2003): Extended longevity in mice lacking the insulin receptor in adipose tissue. Science 299, 572-574 http://dx.doi.org/10.1126/science.1078223

Calabrese E. J., Bachmann K. A., Bailer A. J., Bolger P. M., Borak J., Cai L., Cedergreen N., Cherian M. G., Chiueh C. C., Clarkson T. W., et al. (2007): Biological stress response terminology: Integrating the concepts of adaptive response and preconditioning stress within a hormetic dose-response framework. Toxicol. Appl. Pharmacol. 222, 122-128 http://dx.doi.org/10.1016/j.taap.2007.02.015

Chacón F., Esquifino A. I., Perelló M., Cardinali D. P., Spinedi E., Alvarez M. P. (2005): 24-hour changes in ACTH, corticosterone, growth hormone, and leptin levels in young male rats subjected to calorie restriction. Chronobiol. Int. 22, 253-265 http://dx.doi.org/10.1081/CBI-200053522

Clemens M. G. (1999): Nitric oxide in liver injury. Hepatology 30, $1-5$ http://dx.doi.org/10.1002/hep.510300148

Cohen H. Y., Miller C., Bitterman K. J., Wall N. R., Hekking B., Kessler B., Howitz K. T., Gorospe M., de Cabo R., Sinclair D. A. (2004): Calorie restriction promotes cell survival by inducing SIRT1. Science 305, 390-392 http://dx.doi.org/10.1126/science.1099196

Colman R. J., Anderson R. M., Johnson S. C., Kastman E. K., Kosmatka K. J., Beasley M., Allison D. B., Cruzen C., Simmons H. A., Kemnitz J. W., Weindruch R. (2009): Caloric restriction delays disease onset and mortality in rhesus monkeys. Science 325, 201-204 http://dx.doi.org/10.1126/science.1173635

Cuzzocrea S., Rossi A., Serraino I., Mazzon E., Di Paola R., Dugo L., Genovese T., Calabrò B., Caputi A. P., Sautebin L. (2003): 5-Lipoxygenase knockout mice exhibit a resistance to pleurisy and lung injury caused by carrageenan. J. Leukoc. Biol. 73, 739-746 http://dx.doi.org/10.1189/jlb.1002477

Gems D., Partridge L. (2008): Stress-response hormesis and aging: "that which does not kill us makes us stronger". Cell Metab. 7, 200-203 http://dx.doi.org/10.1016/j.cmet.2008.01.001

Girotti M., Khan N., Mc Lellan B. (1991): Early measurement of systematic lipid peroxidation product in the plasma of major blunt trauma patients. J. Trauma 31, 32-35 http://dx.doi.org/10.1097/00005373-199101000-00007

Hamden K., Carreau S., Ayadi F., Masmoudi H., El Feki A. (2009): Inhibitory effect of estrogens, phytoestrogens, and caloric re- 
striction on oxidative stress and hepato-toxicity in aged rats. Biomed. Environ. Sci. 22, 381-387 http://dx.doi.org/10.1016/S0895-3988(10)60015-3

Hibbs J. B., Taintor R., Vavrin Z., Rachlin E. (1989): Nitric oxide: cytotoxic activated macrophage effector molecule. Biochem. Biophys. Res. Commun. 157, 87-94 http://dx.doi.org/10.1016/S0006-291X(88)80015-9

Hunt P. R., Son T. G., Wilson M. A., Yu Q. S., Wood W. H., Zhang Y., Becker K. G., Greig N. H., Mattson M. P., Camandola S., Wolkow C. A. (2011): Extension of lifespan in C. elegans by naphthoquinones that act through stress hormesis mechanisms. PLoS One 6, e21922 http://dx.doi.org/10.1371/journal.pone.0021922

Laganiere S., Yu B. P. (1989): Effect of chronic food restriction in aging rats II. Liver cytosolic antioxidants and related enzymes. Mech. Ageing Dev. 48, 221-230 http://dx.doi.org/10.1016/0047-6374(89)90084-5

Le Bourg E. (2009): Hormesis, aging and longevity. Biochim Biophys Acta 1790, 1030-1039 http://dx.doi.org/10.1016/j.bbagen.2009.01.004

Ling P. R., Bistrian B. R. (2009): Comparison of the effects of food versus protein restriction on selected nutritional and inflammatory markers in rats. Metabolism 58, 835-842 http://dx.doi.org/10.1016/j.metabol.2009.03.002

Lowry O. H., Rosenbrough N. J., Farr A. L., Randall R. J. (1951): Protein measurement with the folin phenol reagent. J. Biol. Chem. 193, 265-275

Marques F. Z., Markus M. A., Morris B. J. (2009): Hormesis as a pro-healthy aging intervention in human beings? Dose Response 8, 28-33 http://dx.doi.org/10.2203/dose-response.09-021.Morris

Masoro E. J. (1998a): Hormesis and the antiaging action of dietary restriction. Exp. Gerontol. 33, 61-66 http://dx.doi.org/10.1016/S0531-5565(97)00071-5

Masoro E. J. (1998b): Influence of caloric intake on aging and on the response to stressors. J. Toxicol. Environ. Health B. Crit. Rev. 1, 243-257 http://dx.doi.org/10.1080/10937409809524554

Masoro E. J. (2005): Overview of caloric restriction and ageing. Mech. Ageing Dev. 126, 913-922 http://dx.doi.org/10.1016/j.mad.2005.03.012

Masoro E. J., McCarter R. J. M., Katz M. S., McMahan C. A. (1992): Dietary restriction alters characteristics of glucose fuel use. J. Gerontol. Biol. Sci. 47, 202-208 http://dx.doi.org/10.1093/geronj/47.6.B202
Mesquita A., Weinberger M., Silva A., Sampaio-Marques B., Almeida B., Leão C., Costa V., Rodrigues F., Burhans W. C., Ludovico P. (2010): Caloric restriction or catalase inactivation extends yeast chronological lifespan by inducing $\mathrm{H} 2 \mathrm{O} 2$ and superoxide dismutase activity. Proc. Natl. Acad. Sci. U.S.A. 107, 15123-15128 http://dx.doi.org/10.1073/pnas.1004432107

Nisoli E., Tonello C., Cardile A., Cozzi V., Bracale R., Tedesco L., Falcone S., Valerio A., Cantoni O., Clementi E., Moncada S., Carruba M. O. (2005): Calorie restriction promotes mitochondrial biogenesis by inducing the expression of eNOS. Science 310, 314-317 http://dx.doi.org/10.1126/science.1117728

Pompella A., Visvikis A., Paolicchi A., De Tata V., Casini A. F. (2003): The changing faces of glutathione, a cellular protagonist. Biochem. Pharmacol. 66, 1499-1503 http://dx.doi.org/10.1016/S0006-2952(03)00504-5

Radak Z., Chung H. Y., Koltai E., Taylor A. W., Goto S. (2008): Exercise, oxidative stress and hormesis. Ageing Res. Rev. 7, 34-42 http://dx.doi.org/10.1016/j.arr.2007.04.004

Rao G., Xia E., Nadakavukaren M. J., Richardson A. (1990): Effect of dietary restriction on the age-dependent changes in the expression of antioxidant enzymes in rat liver. J. Nutr. 120, 602-609

Ristow M., Zarse K. (2010): How increased oxidative stress promotes longevity and metabolic health: The concept of mitochondrial hormesis (mitohormesis). Exp. Gerontol. 45, 410-418 http://dx.doi.org/10.1016/j.exger.2010.03.014

Ristow M., Schmeisser S. (2011): Extending life span by increasing oxidative stress. Free Radic. Biol. Med. 51, 327-336 http://dx.doi.org/10.1016/j.freeradbiomed.2011.05.010

Sun M., Zigman S. (1978). An improved spectrophotometric assay for superoxide dismutase based on epinephrine autooxidation. Anal. Biochem. 90, 81-89 http://dx.doi.org/10.1016/0003-2697(78)90010-6

Waite K. A., Cabilio N. R., Vance D. E. (2002): Choline deficiencyinduced liver damage is reversible in Pemt(-/-) mice. J. Nutr. $132,68-71$

Weindruch R., Sohal R. S. (1997): Caloric intake and aging. N. Engl. J. Med. 337, 986-999 http://dx.doi.org/10.1056/NEJM199710023371407

Received: February 2, 2012

Final version accepted: January 7, 2013 